\title{
Research on the Wear Mechanism of Ceramic Tool in Turning of Nickel-based Superalloy GH4169
}

\author{
Yubo Liu ${ }^{1,2, a}$ and Yongde Zhang ${ }^{1, b}$ \\ ${ }^{1}$ Harbin university of Science and Technology, Harbin, 150080, China \\ ${ }^{2}$ Heilongjiang university of Science and Technology, Harbin, 150022 China \\ aysclx@126.com, ${ }^{b}$ zhangyd@hrbust.edu.cn
}

\begin{abstract}
The dry cutting experiment for nickel-based high temperature alloyGH4169 was conducted with $\mathrm{Al}_{2} \mathrm{O}_{3}-\mathrm{SiC}_{w}$ whisker toughening ceramic blade $\mathrm{WG} 300$ and $\mathrm{Si}_{3} \mathrm{~N}_{4}-\mathrm{Al}_{2} \mathrm{O}_{3}$ ceramics (Sialon) blade SX9. The main wear mechanism of ceramic cutting tools were analyzed by means of observing the wear morphology about cutting tools with scanning electron microscope, and measuring concentration of each element in wear tiny region lying in the ceramic tools with Energy Dispersive Spectrometer(EDS). The results show that the main wear mechanism of ceramic cutting tool was presented by cohesive wear, abrasive wear and oxidation wear. Cohesive wear occurs mainly on the rake face and were influenced by the contact stress state between the contact points of cutting tool and workpiece material.
\end{abstract}

Keywords: superalloy, ceramic-cutting tool, wear mechanism

\section{Introduction}

Today nickel-base superalloy plays an increasingly important role in aerospace. Because of its excellent performance, GH4169 was widely used in the casing, turbines, combustion chamber, the space shuttle, nuclear reactors and other high temperature applications. However, for some problems, such as high cutting temperature, cutting forces, serious hardening problem and lower cutting tool life and so on, existing in the cutting process of GH4169 as a consequence, GH4169 becomes one of typically difficult materials. How to improve cutting efficiency, processing quality and extend tool life has been a key issue needed to be urgently addressed in GH4169 processing, but also one of measures enhancing the level of manufacturing process in aviation and aerospace.

In this paper, by studying the wear mechanism of tool and analyzing the main forms of tool wear in the speed turning $\mathrm{GH} 4169$ with $\mathrm{Al}_{2} \mathrm{O}_{3-} \mathrm{SiC}_{\mathrm{W}}$ whisker reinforced ceramic blade WG300 and $\mathrm{Si}_{3} \mathrm{~N}_{4}-\mathrm{Al}_{2} \mathrm{O}_{3}$ ceramic (Sialon) blade $\mathrm{SX} 9$, the theoretical basis and technical support for material selection about high-temperature alloy machining tool, design about tools structure and optimization of cutting parameters were provided.

\section{Experimental Program}

\subsection{Cutting Conditions}

Experiments were on EMCO-Maxxturn 65 Turning Center, Machine maximum speed: 5000r/min; Cutting conditions for dry cutting. A nickel-based superalloy GH4169 bar was selected as the workpiece material for the experiment, of which heat treatment is solution and aging. 
Hardness: 40HRC; Workpiece size: $\phi 140 \mathrm{~mm} \times 250 \mathrm{~mm}$; The chemical composition of the workpiece material as shown in Table 1.

Table 1. The Main Chemical Components of Nickel-based Superalloy GH4169 wt\%

\begin{tabular}{|c|c|c|c|c|c|}
\hline Composition & Content & Composition & Content & Composition & Content \\
\hline $\mathrm{C}$ & $\leq 0.08$ & $\mathrm{Ti}$ & $0.75 \sim 1.15$ & $\mathrm{Si}$ & $\leq 0.35$ \\
\hline $\mathrm{Cr}$ & $\begin{array}{c}17.0 \sim 21 . \\
0\end{array}$ & $\mathrm{Nb}$ & $4.75 \sim 5.50$ & $\mathrm{P}$ & $\leq 0.015$ \\
\hline $\mathrm{Ni}$ & $\begin{array}{c}50.0 \sim 55 . \\
0\end{array}$ & $\mathrm{Al}$ & $0.30 \sim 0.70$ & S & $\leq 0.015$ \\
\hline Co & $\leq 1.0$ & B & $\leq 0.006$ & $\mathrm{Cu}$ & $\leq 0.30$ \\
\hline Mo & $\begin{array}{c}2.80 \sim 3.3 \\
0 \\
\end{array}$ & $\mathrm{Mg}$ & $\leq 0.01$ & $\mathrm{Fe}$ & $\sim$ \\
\hline
\end{tabular}

\subsection{Tool Material}

$\mathrm{Al}_{2} \mathrm{O}_{3}-\mathrm{SiC}$ whisker reinforced ceramic blade WG300 and $\mathrm{Si}_{3} \mathrm{~N}_{4}-\mathrm{Al}_{2} \mathrm{O}_{3}$ ceramic (Sialon) blade SX9 was selected as the main cutting tools in the experiment .The tool models are that: SNGN 120416T01020.The form of blade cutting edge is chamfered and chamfer width of $0.1 \mathrm{~mm}$, down angularity $20^{\circ}$, The model equipped with a blade shank was: CSRNR 2020K 12 , After installation of blade, Rake angle of $-6^{\circ}$, posterior horn of $6^{\circ}, 75^{\circ}$ Blade angle to- $6^{\circ}$; main angle: $75^{\circ}$..After the cutting process, the tool flank wear values were measured under the use of Dino-Lite digital microscope and the blunt standard was set as : The average wear value in flank $\mathrm{VB} \geq 0.3 \mathrm{~mm}$, wear value in Groove $\mathrm{VN} \geq 0.6 \mathrm{~mm}$. To the blade achieving the standard of blunt, its observation and analysis about overall wear morphology were conducted by utilizing the scanning electron microscope (SEM) and Energy Dispersive Spectrometer (EDS).The experimental site is shown in Figure 1. And the experimental arbor is shown Figure 2.
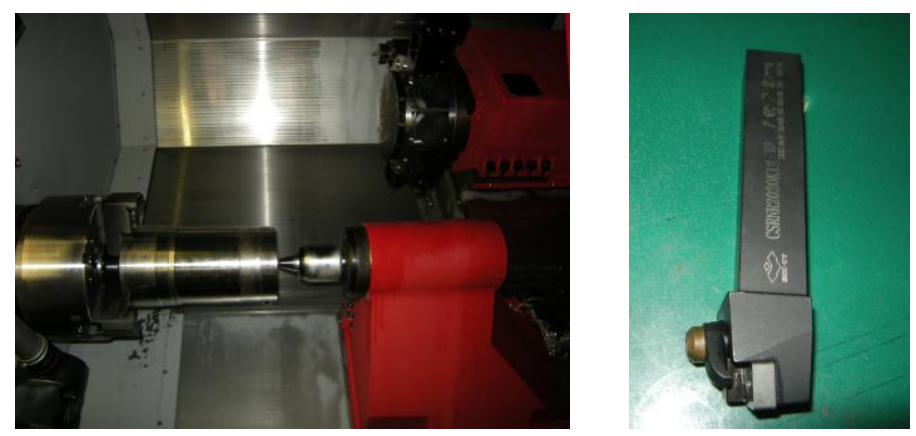

Figure 1. Experimental Site

Figure 2. Experimental Arbor

\section{Analysis}

\subsection{Abrasive Wear}

Abrasive wear was that the workpiece surface was sheared and plowed by friction and then the trough-like indentation was generated by the abrasive action of furrows when hard particles in the workpiece are pressed into the friction surface, under the action of some 
certain loads, and then slided. As Figure 3 shows. SEM photograph of flank wear in cutting speed $250 \mathrm{~m} / \mathrm{min}$ happened in WG300. The degree of adhesion of workpiece material at flank wear belt was relatively severe.

The morphology of tool wear is covered by the workpiece material however from a view of attrited edges, some attrited grooves would be found. The attrited grooves of SX9 in cutting speed $250 \mathrm{~m} / \mathrm{min}$ was showed in Fig.4.The surface of attrited belts, which happened in the flank of the tool, under the power of Abrasive wear, showed apparent ditch ridge and adhered crushing workpiece material.

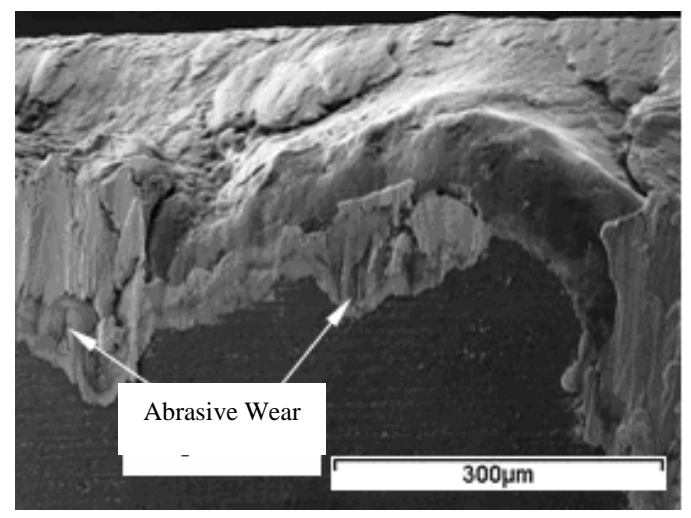

Figure 3. Abrasive Wear in WG300

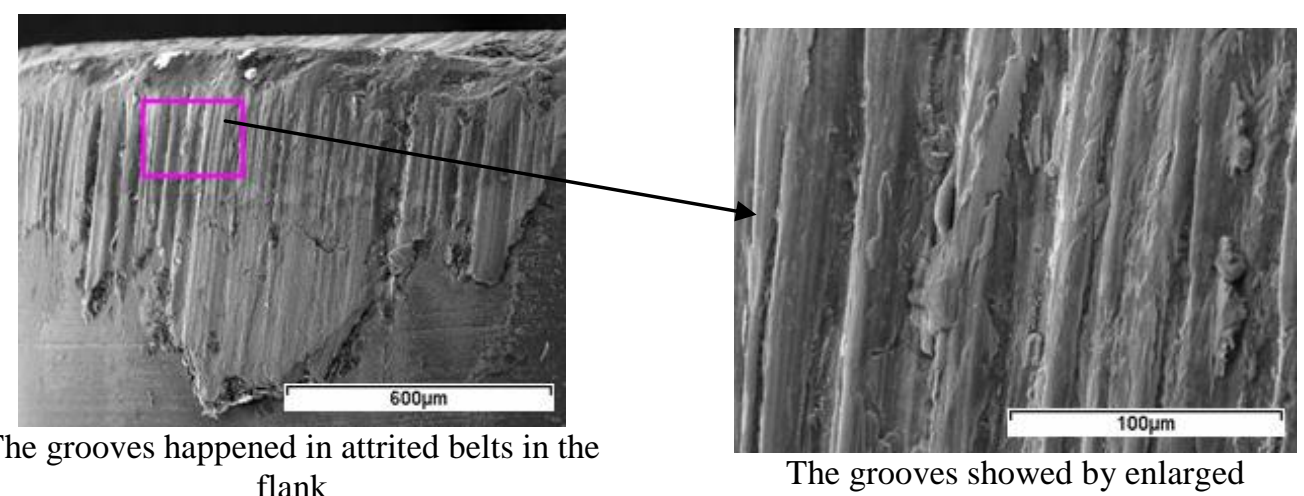

Figure 4. Abrasive Wear in SX9

What cause abrasive wear of ceramic tools are that: Carbides, nitrides and other small refractory hard particles, which exit in Nickel-based superalloy GH4169, could maintain higher hardness, under the conditions of high temperature. In the cutting process, the hard particles work at the surface of tool as plowing and scribing, and draw on the tool surface grooves .At the same time, when tool was in the event of chipping or peeling, material particles from the tool, which were shed from tool matrix material and were sandwiched between the tool and the workpiece material. The particles, driven by the surface of the chip or transition, would also draw on the tool surface grooves when flow through the tool surface. For SX9, from the tool chipping range, it could be fund that the range distributed by grooves along the cutting edge was consistent with that of tool chipping. Therefore, the effect of plowing and scribing, caused by particles off from the substrate itself, is the main cause of abrasive wear SX9. The hard particles, contained in nickel-base alloy workpiece, scratch the tool flank along the direction of movement of the tool relative to the workpiece. The lower 
the frequency of peeling happened in the cohesive layer, the more clear the scratches and even attrited stripes are formed.

\subsection{Cohesive Wear}

Cohesive wear is the phenomenon produced by contacts, whose distance was at the atoms, of tool and the workpiece material, and that so-called cold welding happened in the actual contact area of the friction surface and when plastic deformation was bring about at a sufficient pressure and temperature.

When WG300 was in $190 \mathrm{~m} / \mathrm{min}$ and $310 \mathrm{~m} / \mathrm{min}$ cutting speed, the attrited morphology of trench edge in flank was shown as Figure 5 (a) and 5 (b). As can be seen from the figure, Clear dents was formed by the action of tearing bonding in the edge of the grooves .The reason due to cohesive wear is the lower shear and tensile strength of ceramic tools, therefore, in the conditions of occurrence of cold welding cutting between workpiece and tools, shear failure in the process of cold welding will cause the sticking and eclipsing in the surface of ceramic tools and then relative motion was happened among the cohesive points in double friction surface, and then the crystal grain or crystal grain group was taken away by the other party for being sheared or tensed.

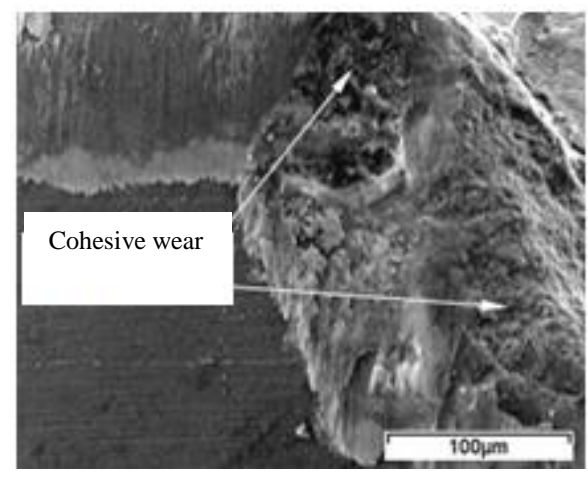

(a)Cutting speed $190 \mathrm{~m} / \mathrm{min}$

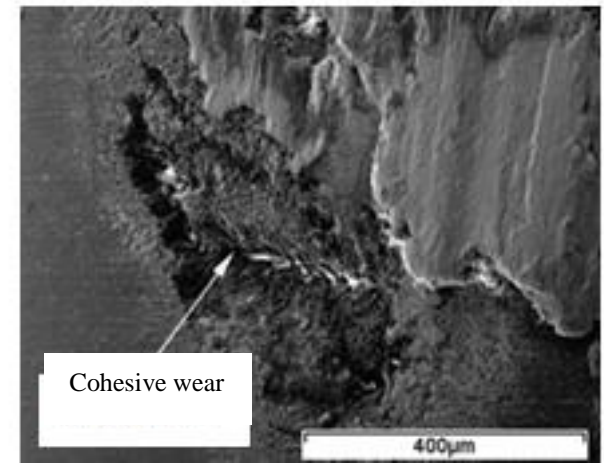

(b)Cutting speed $310 \mathrm{~m} / \mathrm{min}$

Figure 5. Cohesive Wear in WG300

Analyzed from the point of view the temperature-thermal stress, cutting force withstand by tools, when cutting nickel-based alloy GH4169 in high speed, is much larger than that when cutting ordinary cutting materials. Temperature of the rake face was about $1200{ }^{\circ} \mathrm{C}$ when cutting nickel-based alloy GH4169 in 190m/min cutting speed, and temperature of the flank was about $1250 \sim 1300{ }^{\circ} \mathrm{C}$. When cutting in $310 \mathrm{~m} / \mathrm{min}$ cutting speed. Therefore, the temperature in cutting zone is much higher and the cutting heat increases substantially when cutting nickel-based alloy. Adhesion between blade and chipping materials occurs for the cutting heat produced in the process of blade cutting and stress caused by temperature gradient and for that cohesive wear will generate and expand quickly.

\subsection{Chemical Reaction and Dispersion Wear}

The dispersion processes are involved in the process by the heat .When cutting GH4169 in the high speed, the cutting heat is very high. The close contact between blade-crumbs and blade-workpiece provide an ideal environment, in which atoms in tool material could diffused to out though blade-crumbs. 
It can be seen that, from the Wear morphology about Ceramic tools $\mathrm{Al}_{2} \mathrm{O}_{3}-\mathrm{SiC}_{\mathrm{w}}$ Whisker WG300 and Sailon SX9, obtained in each group of cutting parameters, workpiece material will form a uniform adhesion in cohesive area between tools rake face and flank. After the analysis of cohesive material composition in tool wear area by Scanning Electron Microscopy and Energy Dispersive Spectrometer, it can be found there are not only cohesive workpiece materials in wear areas between WG300 and SX9 but also a region lying in the local position in which a large number of $\mathrm{Ti}$ was gathered in.

For $\mathrm{Al}_{2} \mathrm{O}_{3}-\mathrm{SiC}_{\mathrm{w}}$ Whisker ceramic tools WG300, Ti-rich region located under the edge of the flank wear belts. The analyzed results about Measuring points, in the wear area in blade of WG300 in the cutting speed $190 \mathrm{~m} / \mathrm{min}$ and $310 \mathrm{~m} / \mathrm{min}$, were showed as Fig.6 and Fig.7.The content of $\mathrm{Ti}$ elements was very high, but the content of $\mathrm{Ni}, \mathrm{Fe}$ and $\mathrm{Cr}$, originally more content in GH4169 workpiece material, was very low .The Ti elements in the area only comes from the work piece GH4169, but its original contents was only accounted for about $1 \%$ of GH4169 element content.

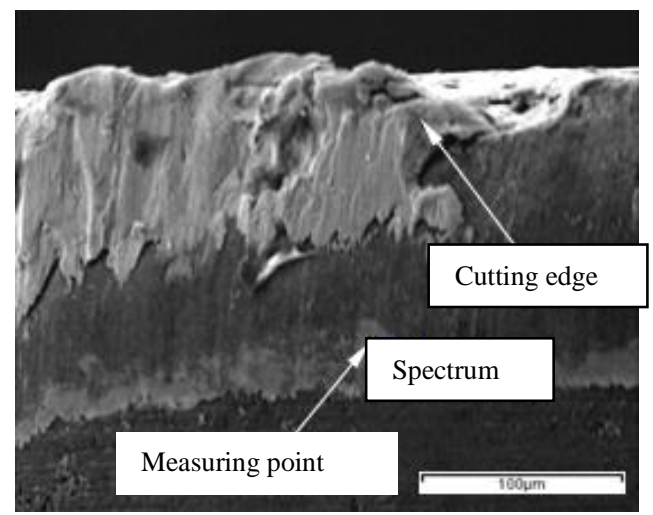

(a) measuring point in wear belt in flank

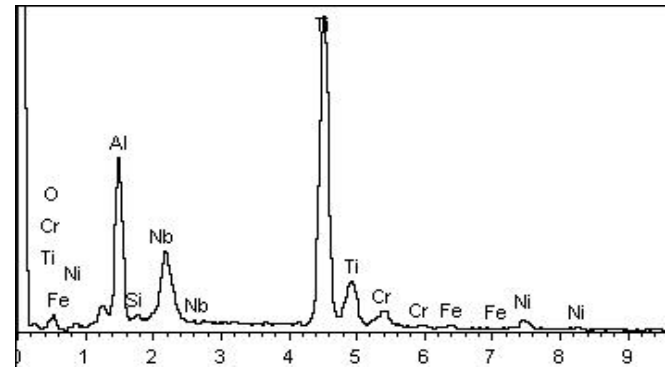

(b)Analysis about component of measuring point

Figure 6. Analysis about Measuring Point in Wear Belt in Flank in the Cutting Speed $190 \mathrm{~m} / \mathrm{min}$

For Sailon ceramic tools SX9, there is no white ribbon under the edge of the flank wear belts. However it is can be fund that the area, under some areas in wear region, in which a large number of contents of Ti elements was layed in. Ti-rich region in rake was found in the area between cohesive area in workpiece and on adhered area.

The analyzed results about Measuring points, in the wear area in blade of SX9 in the cutting speed $150 \mathrm{~m} / \mathrm{min}$ and $200 \mathrm{~m} / \mathrm{min}$, were showed as Figure 8 and Figure 9 . Compared to other elements of the workpiece material, The contents of Ti-elements in the cohesive material in wear area were still very high. 


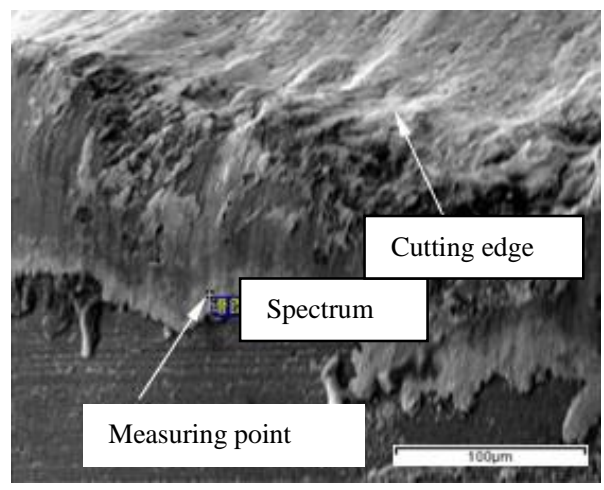

(a)measuring point in wear belt in flank

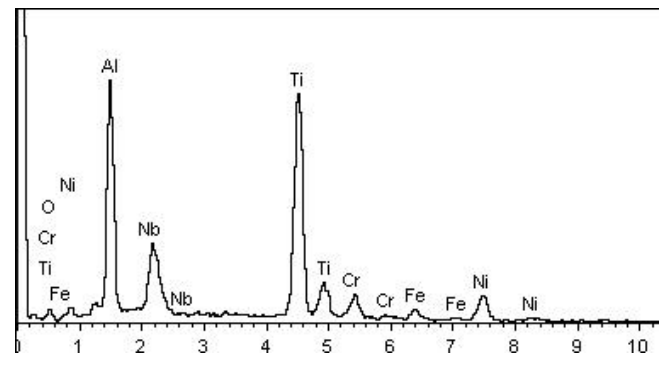

(b)Analysis about component of measuring point

Figure 7. Analysis about Measuring Point in Wear Belt in Flank in the Cutting Speed $310 \mathrm{~m} / \mathrm{min}$ WG300

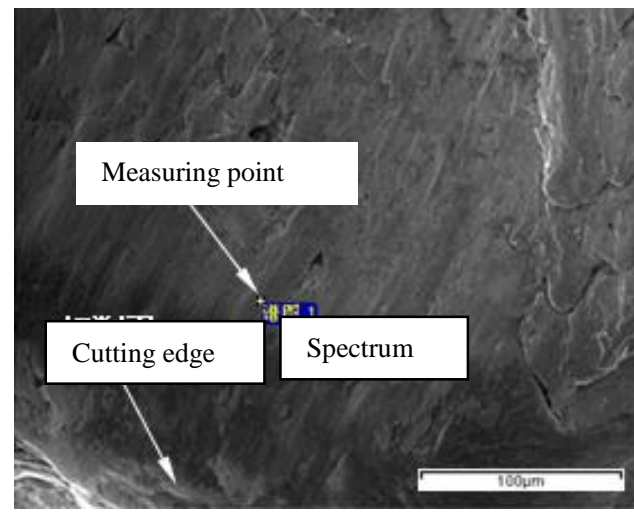

(a)Crater measuring point in blade

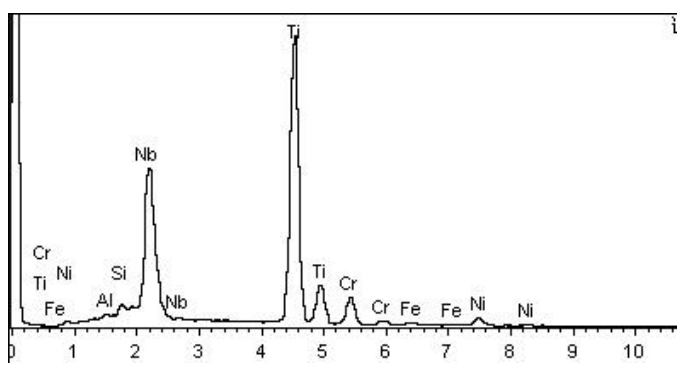

(b)Analysis about component of measuring point

Figure 8. Analysis about Measuring Point in Wear Belt in Flank in the Cutting Speed $150 \mathrm{~m} / \mathrm{min}$ SX9

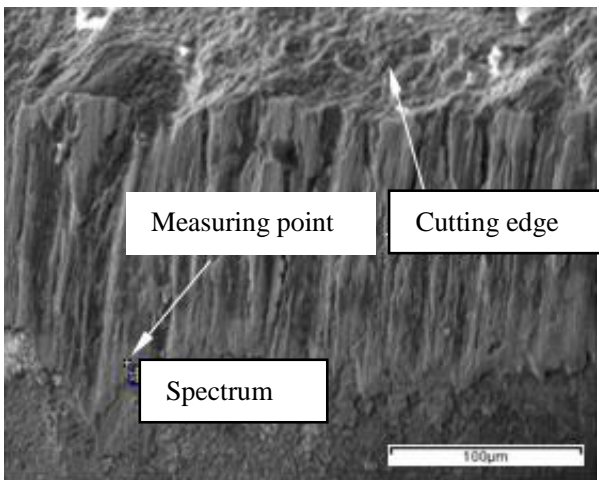

(a)measuring point in wear belt in flank

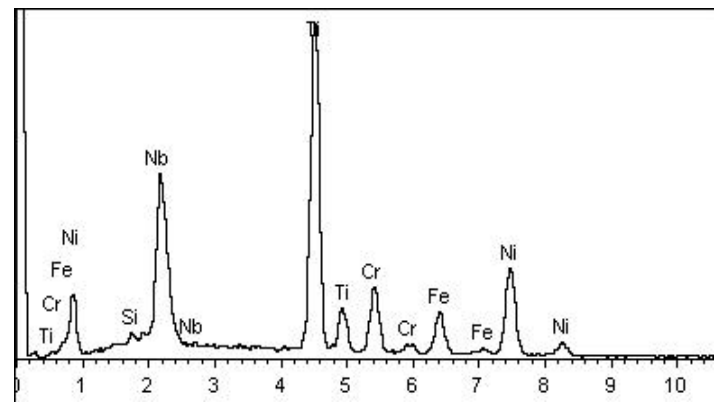

(b)Analysis about component of measuring point

\section{Figure 9. Analysis about Measuring Point in Wear Belt in Flank in the Cutting Speed $200 \mathrm{~m} / \mathrm{min}$ SX9}

Cause about appearance of Ti-rich region: When $\mathrm{Al}_{2} \mathrm{O}_{3}-\mathrm{SiC}_{\mathrm{w}}$ Whisker ceramic tools cuts nickel-base superalloy Inconel 718, the elements $\mathrm{Fe}, \mathrm{Cr}$ and $\mathrm{Ni}$ in Inconel 718 are spread to 
matrix of tool along the $\mathrm{SiC}$ whisker and react with $\mathrm{SiC}$ whisker to generate silicide and then $\mathrm{SiC}$ whisker was dissolved. The elements of $\mathrm{Ti}$ and $\mathrm{Nb}$ in GH4169 would react with the element $\mathrm{C}$ generated in the process of dissolving of $\mathrm{SiC}$ whisker to accumulate in the surface of tools in the form of the carbides.

Meanwhile, when milling nickel base super alloy GH4169 with Sailon ceramic cutting tool, $\mathrm{Si}_{3} \mathrm{~N}_{4}$ grain will be dissolved for the elements like $\mathrm{Fe}, \mathrm{Cr}$ and $\mathrm{Ni}$ in GH4169 diffuse into cutting tool substrate along the ceramic grain boundary, while the cutter surface gathers nitrides that caused by the reaction of the element $\mathrm{N}$ in cutting tool substrate and the elements like $\mathrm{Ti}$ and $\mathrm{Nb}$ in nickel base alloy. However, in the process of milling nickel base super alloy with ceramic cutting tool, the high temperature in cutting area behinds the diffusion wear.

\section{Conclusions}

When milling nickel base super alloy with $\mathrm{Al}_{2} \mathrm{O}_{3}-\mathrm{SiC}_{\mathrm{w}}$ whisker toughening ceramic cutting tool and Sailon ceramic cutting tool, chemical reaction and element diffusion will be existed between cutter material and workpiece material, and the strength and toughness of the cutting tool substrate will be reduced for the dissolution of $\mathrm{SiC}_{\mathrm{w}}$ whisker and $\mathrm{Si}_{3} \mathrm{~N}_{4}$ grain in the ceramic cutting tool, which leading to the decline of the tool wear resistance.

In the element diffusion process, beneficiation of cutter surface on Ti element in the workpiece material is obvious, which appears the diffusion indirectly in the area local position of WG300 and SX9, resulting the cutting tool substrate be added main elements like $\mathrm{Ni} 、 \mathrm{Fe} 、 \mathrm{Cr}$ from workpiece material and Ti element separates out on the cutter surface.

With the scratch of cuttings and transitional surface, on the cutter surface, the educt will be peeled by shear, in the area of cutter surface where shear force is large enough, it will be cleared, and in the location of less shear force, it could still attach to the surface.

\section{Acknowledgements}

This research was supported by the National Science Foundation of Heilongjiang Province (Project No QC2012C029) and the Education Department Project of Heilongjiang Province(12541699).

\section{References}

[1] D. Q. Gao, Z. Y. Li and Z. Y. Mao, "Cutting Performance Analysis and Parameter Optimization on Nickelbaded Alloy High-speed Cutting", Modular Machine tool Automatic Manufacturing technique, vol. 12, (2010), pp. 10-12.

[2] M. Nalbant, A. Altin and G. H. Kaya, "The effect of cutting speed and cutting tool geometry on machinability properties of nickel-base Inconel 718 super alloys Materials \& Design”, vol. 28, no. 4, (2007), pp. 1334-1338.

[3] A. Altin and M. Nalbant, "The effects of cutting speed on tool wear and tool life when machining Inconel 718 with ceramic tools.Materials and Design”, vol. 28, (2007), pp. 2518-2522.

[4] T. Kitagawa, A. Kubo and K. Maekawa, "Temperature and wear of cutting tools in high speed machining of Inconel and Ti-6Al-6V-2Sn", Wear, vol. 202, no. 2, (1997), pp. 142-148.

[5] Y. B. Liu, Y. D. Zhang and C. Zhao, "Experimental study on Milling force of Nickel-based high-temperature alloy GH3039”, Advanced Materials Research, vol. 9, (2013), pp. 3-8.

[6] G. Brandt, A. Gerendas and M. Mikus, "Wear mechanisms of ceramic cutting tools when machining ferrous and non-ferrous alloys", Journal of the European Ceramic Society, vol. 6, no. 5, (1990), pp. 273-290.

[7] L. Weimin, Z. Jun and A. Xing, "Wear Mechanisms of Al2O3-Based Ceramic Cutting Tool in High Speed Turning of 300M Ultra High Strength Steel" Tribology, vo. 6, no. 11, (2010), pp. 564-568.

[8] G. Xuhong, R. Yannian and Z. Shengling, "Study on Ceramic Cutter's Wear Mechanism When Dry Cutting Austempered Ductile Iron (ADI)", Tribology, vol. 26, no. 1, (2006), pp. 73-78.

[9] W. Jufeng and Z. Xianfeng, "He Lin and Li Changhong, Study on Milling Parameters Optimization of Supper Alloy Inconel GH4169”. Modern manufacturing processes and equipment, vol. 2, (2010), pp. 1-3. 
[10] W. Yi and A. Xi. "Tool wear and fracuter in high speed milling aluminum alloy", 7050-T7451, Chinese journal of mechanical engineering, vol. 43, no. 4, (2007), pp. 103-107.

[11] R. S. Pawade, S. Suhas and P. K. Joshi, "An investigation of cutting forces and surface damage in high-speed turning of Inconel718”, Journal of Materials Processing Technology, vol. 50, (2007), pp. 139-146.

[12] V. Sehulze, H. Autenrieth and M. Deuchert, "Investigation of surface near residual stress states after microcutting by finite element simulation", CIPP Annals-Manufacturing Technology, vol. 59, (2010) pp. 117-120.

[13] X. Zhao, "Cutting of Nickel-Based High Temperature Alloy, Aeronautical manufacturing technology, vol. 11, (2010).

[14] J. P, "Tool-life and wear mechanisms of CBN tools in machining of Inconel718", Machine Tools \& Manufacture, vol. 47, (2007), pp. 1081-1087.

[15] R. T. Coelho, L. R. Silva, A. Braghini Jr. and A. A. Bezerra, "Some effects of cutting edge preparation and geometric modifications when turning Inconel 718 at high cutting speeds", Journal of Materials Processing Technology, vol. 148, no. 1, (2004), pp. 147-153.

[16] N. Ahemad, A. V. Mitrofanov, V. I. Babitsky and V. V. Silberschmidt, "Analysis of material response to ultrasonic vibration loading in turning Inconel 718", Material Science and Engineering, vol. 242, (2006), pp. 318-325.

[17] X. AI, Editor, "High speed Machining technology", National defense Industry Press China, (2003).

[18] Z. J Yuan, Metal, Editor, “Cutting experiment techniques”, Machinery Industry Press, China, (1988).

[19] A. Alique, R. E. Haber, S. Ros and C. Gonzalez, Editors, "A neural network based model for the prediction of cutting force in milling process, a progress study on a real case", Proceedings of the 15th IEEE International Symposium on Intelligent Control, (2000) July 17-19. 